\title{
Quebec will lose doctors if secular charter becomes law
}

$\mathrm{M}$ edical residents in Quebec have joined doctors and hospitals to stand against the province's proposed Charter of Values, which would prohibit health workers from wearing religious symbols at work.

The prohibition "constitutes a totally unwarranted restriction on a fundamental right," objected Dr. Joseph Dahine, president of the Fédération des médecins résidents du Québec (FMRQ), at a Feb. 12 parliamentary committee hearing.

The group, which represents 3600 medical residents in the province, supports a clear separation of religion and state, said Dahine. "But it is this very religious neutrality that we feel is under attack," as the proposed charter would "discriminate against those for whom wearing religious symbols is an important component in their exercise of religious freedom."

Should such "discriminatory restrictions" become law, he warned an exodus of physicians is likely to follow. "A number of medical residents have already made it clear that they might have to leave Quebec's medical schools to pursue their training elsewhere if such a measure were to come into effect, in order to be able to continue living and working in accordance with their religious convictions."

The concern was echoed in a statement to $C M A J$ by Dr. Laurent Marcoux, president of the Association médical du Québec. He wrote that "adopting and applying Bill 60 will affect the availability of resources, which will disrupt services for patients ... [and] very likely lead to a decrease in care."

Marcoux added that the bill shouldn't apply to physicians at all, as they are selfemployed workers, not civil servants.

Proponents of the charter contend that no individual representing the state in any capacity should express religious affiliation while on the clock. According to Bernard Drainville, the Parti Québécois cabinet minister responsible for the proposed legislation, such measures are necessary to create a truly

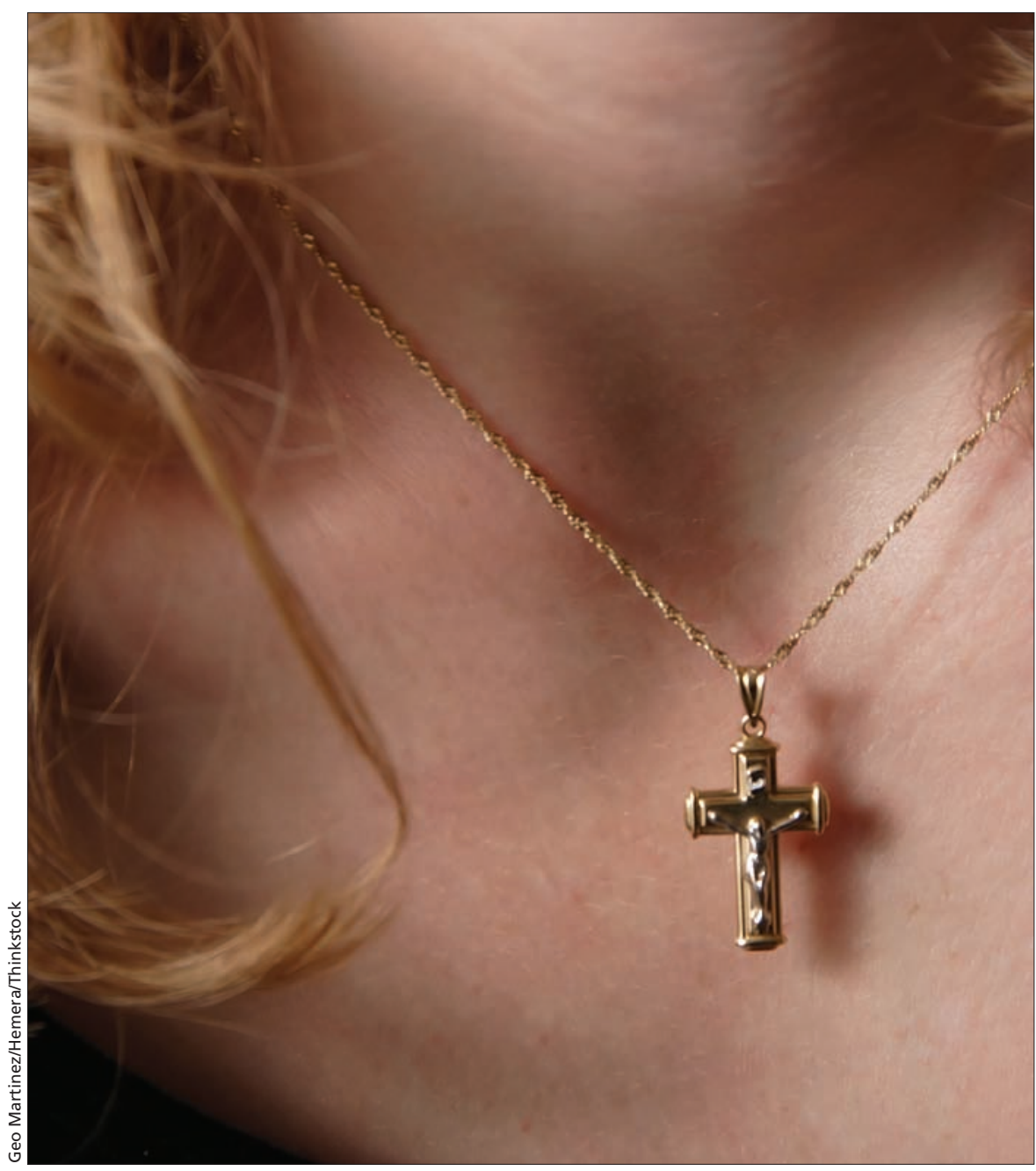

A proposed Quebec law would ban physicians from wearing religious symbols at work, although some smaller items of jewelry may be exempt.

secular democracy in which citizens are protected from discrimination.

But Dahine questions how much additional protection the charter could grant, given that physicians have a professional obligation to treat patients "regardless of age, gender, sexual orientation [or] religion, and there are already mechanisms in place to deal with doctors that refuse to treat a patient based on discriminatory grounds."

Residents confirmed in a recent FMRQ consultation that religious garb in the workplace posed "no problem for them whatsoever and had no impact on the quality of care they deliver."
The McGill University Health Center in Montréal, Quebec, has also requested that the bill be withdrawn, charging that the ban on religious garb runs contrary to the Quebec Charter of Human Rights and Freedoms, and would affect the hospital's international reputation and ability to provide care. A December 2013 statement also cited concern over "repeated comments received from employees that are planning to leave the province should the bill be enacted." - Patrick Janukavicius, Montréal, Que.

CMAJ 2014. DOI:10.1503/cmaj.109-4737 